\title{
The influence of the condylar fracture treatment method on mandible dynamics
}

\section{Wpływ metod leczenia złamania kłykciowego na dynamikę ruchów żuchwy}

\author{
Jakub Krzemien'1,A-D, Łukasz Bańczyk ${ }^{1, A-C}$, Stefan Baron 2,E,F, Iwona Niedzielska, ${ }^{1, D-F}$ \\ ${ }^{1}$ Department of Cranio-Maxillofacial Surgery, Medical University of Silesia, Katowice, Poland \\ ${ }^{2}$ Department of Temporomandibular Disorders and Orthodontics, Medical University of Silesia, Katowice, Poland \\ A - research concept and design; $\mathrm{B}$ - collection and/or assembly of data; $\mathrm{C}$ - data analysis and interpretation; \\ $D$ - writing the article; $\mathrm{E}$ - critical revision of the article; $\mathrm{F}$ - final approval of the article
}

Address for correspondence

Jakub Krzemień

E-mail: szczekowo-twarzowa@sum.edu.pl

Funding sources

None declared

Conflict of interest

None declared

Received on September 29, 2017

Reviewed on 0ctober 7, 2017

Accepted on November 22, 2017

DOI

$10.17219 / \mathrm{dmp} / 80748$

Copyright

() 2017 by Wroclaw Medical University

and Polish Dental Society

This is an article distributed under the terms of the

Creative Commons Attribution Non-Commercial License

(http://creativecommons.org/licenses/by-nc-nd/4.0/)

\section{Abstract}

Background. Among commonly adopted condylar fracture treatment methods, there is the open reduction and closed reduction method. For the purpose of evaluating the therapeutic effect of a given method and the functional state of the temporomandibular joints, it is possible nowadays to conduct an instrumental analysis with the use of modern devices such as the axiograph.

Objectives. The study was aimed at a long-term assessment of the function of the stomatognathic system, in particular assessment of the range of the condylar path in the temporomandibular joints, depending on the method of condylar fracture treatment (open or closed).

Material and methods. The study involved 60 patients in total (mean age in the study group was 33.3 years), including 24 women (40\%), who were divided into 2 groups. The $1^{\text {st }}$ group included 40 patients in whom condylar fractures were surgically managed. The other group consisted of 20 patients in whom the closed reduction method of treatment was applied. Patients were qualified for surgery under general anesthesia or for treatment by means of standard splints and maxillomandibular fixation. After 6 months following the conclusion of treatment, each patient was scheduled for a follow-up appointment, during which an axiographic examination aimed at the registration of the condylar path in the temporomandibular joints was performed. The values registered were subject to a statistical analysis and compared between the groups.

Results. A significant difference ( $F=5.36 ; p=0.0241)$ in the length of the condylar path in the sagittal plane was observed, depending on the method of condylar fracture treatment. In the case of open reduction, the values were higher than in the case of closed reduction.

Conclusions. Miniplate osteosynthesis disturbs the mandibular dynamic pattern to a lesser degree but the technique should constantly be improved in order to limit the traumatization of sensitive periarticular structures.

Key words: axiography, temporomandibular joint, mandibular condyle fracture

Słowa kluczowe: aksjografia, staw skroniowo-żuchwowy, złamanie wyrostka kłykciowego żuchwy 
As it follows from epidemiological data, mandibular fractures constitute about $2 / 3$ of all fractures in the craniofacial area. The mandible, although it is a bone characterized by considerable strength, often undergoes injuries due to its location and the lack of protection from other structures. Among mandibular fractures, a specific group of condylar fractures, statistically constituting about $25-35 \%$ of the whole group, can be distinguished. ${ }^{1-3}$ The majority of these fractures occurs indirectly through the application of force in a remote site (usually in the mental region), therefore condylar fractures are the most frequently diagnostically overlooked type of mandibular fracture (Fig. 1). ${ }^{4}$ In spite of the known epidemiological and clinical features of the above fractures, the discussion on a method of their treatment is still in progress. Among the available methods, the open reduction method (surgical) and the closed reduction method (standard splints and maxillomandibular fixation) can be distinguished. Due to the considerable development of surgical techniques, equipment and materials, and as a result of the increasingly smaller invasiveness of the surgery itself, the open reduction treatment of condylar fractures by means of miniplate osteosynthesis is becoming more and more popular. ${ }^{5}$ Stable miniplate osteosynthesis eliminates the necessity of using maxillomandibular fixation, which preserves the function of the temporomandibular joints (TMJs), the muscles of the stomatognathic system, and ensures better nutritional conditions for the patient. ${ }^{6}$ Therefore, it would seem that it is the gold standard of treatment. It should be taken into account, however, that the surgical fixation of fragments, although it enables early TMJ mobilization, also involves the potential risk of damaging the structures of the joint area such as the facial nerve, masticatory muscles or articular disc, which may have an influence on the later rehabilitation of the stomatognathic system. ${ }^{7-9}$

The specificity of mandibular fracture treatment, and particularly of condylar fractures, consists of, on one hand, the early repositioning and fixation of bone fragments, and on the other hand, the earliest possible mandibular mo-

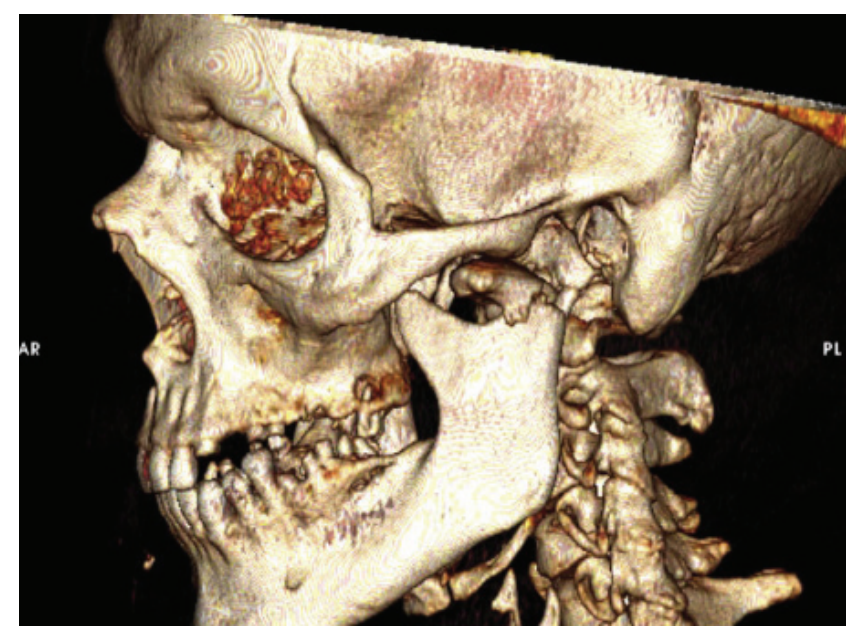

Fig. 1. Fracture of the left mandibular condylar process in CT reconstruction bilization, aimed at enabling the basic functions of the stomatognathic system such as mastication, speaking and swallowing. The fundamental functional and morphological element of the stomatognathic system which ensures the performance of the above-mentioned functions are the temporomandibular joints. The proper function of TMJ and the complexity of its movements (the rotational and translational components) result not only from their characteristic structure but also from their interdependence on the remaining structures of the stomatognathic system, particularly muscles and occlusion. ${ }^{10}$ Therefore, it can be assumed that the functional state of the temporomandibular joint (TMJ) is an important marker of the functioning of the stomatognathic system as a whole.

In order to characterize the function of the temporomandibular joint and the mandibular dynamic pattern precisely, an instrumental analysis with the use of modern devices such as the electronic axiograph can presently be carried out (Fig. 2). The so-called condylar path is registered each time in the course of the opening movement of the mandible, protrusion and laterotrusion (mediotrusion). ${ }^{11-14}$ On the basis of long-term research, Slavicek draws attention to the repetitiveness of graphs obtained in the axiographic examination and suggests that the condylograph, that is the dynamic pattern of the condylar movement, can possess a diagnostic value in itself. ${ }^{10,11}$ Numerous studies have made it possible to determine the proper (physiological) range of the condylar path, which enables the objectivization of research conducted with the use of this data. The range and character of the condylar path can be influenced by masticatory muscles, pain of TMJ and acoustic symptoms - TMJ clicks (dislocations of the articular disc) - as well as restrictions of mandibular mobility of various origin. ${ }^{11-13}$ In the available literature, there is a scarcity of reports on the impact of the method of condylar fracture treatment on the length of the TMJ condylar path. ${ }^{15}$

The aim of this study was a long-term assessment of the functioning of the stomatognathic system (especially assessment of the range of the TMJ condylar path), depending on the method of condylar fracture treatment.

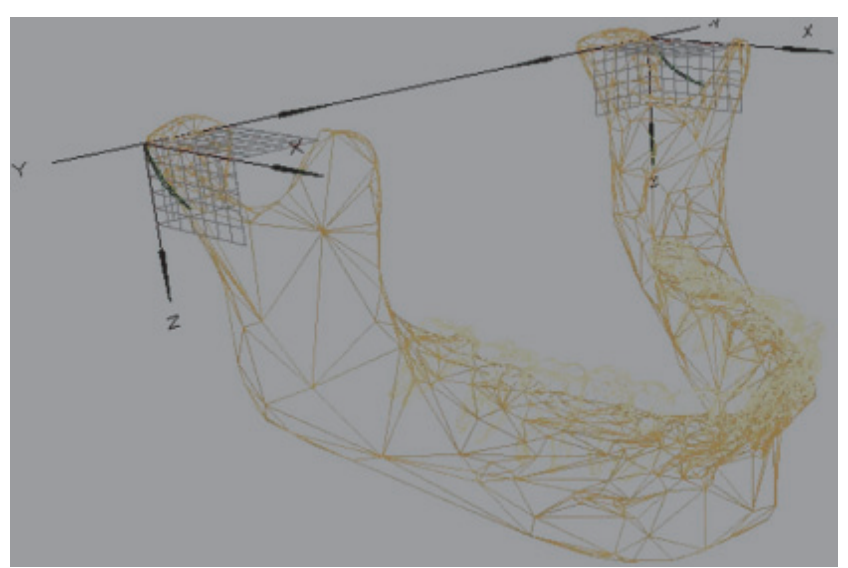

Fig. 2. Axiographic examination enables the registration of the condylar path in 3 planes - sagittal, frontal and horizontal (according to Gamma Dental/Cadiax Compact $\|^{\circledR}$ ) 


\section{Material and methods}

The study was conducted in the Department of CranioMaxillofacial Surgery and Dental Surgery of the Autonomous Public Hospital of the Medical University of Silesia in Katowice, Poland, in the period from May 2016 to May 2017. Sixty patients were included in the study. Mean age in the study group was 33.3 years and the total age range was from 16 to 62 years. The subjects were divided into 2 groups:

- 40 patients with condylar fractures treated surgically were qualified to the open reduction group (group 1);

- 20 patients treated by closed reduction, in whom standard splints and elastic maxillomandibular fixation were used for a period of 4 weeks on average (group 2). The exclusion criteria were as follows:

- history of diseases/disorders of the temporomandibular joints;

- systemic diseases;

- craniofacial traumas in the past;

- occlusion making it impossible to mount the axiograph - supraocclusion, edentulism.

A thorough physical examination, including elements of the functional test of the stomatognathic system, were carried out in each patient. The subsequent stages of the examination included: a general and detailed anamnesis, an analysis of the trajectory and range of mandibular opening, palpation of the masticatory muscles and palpation and auscultatory examination of the temporomandibular joints, and an intraoral check (occlusion analysis, marking of the tooth chart). Additional X-ray diagnostic examinations (panoramic radiographs, mandibular PA, oblique lateral projection of the mandible, $\mathrm{CBCT}$ of the facial skeleton) were performed in order to determine the type of fracture. The characteristic symptoms of condylar fractures, that is occlusion defects (open bite), restricted mandibular opening and facial asymmetry were observed. The type of fracture was determined according to an elaborated classification based on Lindahl's classification, which distinguishes the following types of fractures: condylar head fractures, condylar neck fractures and subcondylar fractures. ${ }^{1}$ Then the subjects were qualified for open reduction (group 1) or closed reduction (group 2).

Open reduction treatment was carried out under general anesthesia. Each time, an incision surrounding the mandibular angle (retromandibular incision) was employed. Fractured condylar processes were fixed with miniplates (Synthes ${ }^{\circledR}$, DePuy Synthes Companies, Massachusetts, USA) or trapezoidal plates (Medartis ${ }^{\circledR}$, AG, Basel, Switzerland). Each time, passive mandibular mobility and the patient's occlusion obtained were checked, and drainage and multiple layer suturing of the wound were applied. X-ray documentation, aimed at checking the correctness of the fixation carried out, was performed (Fig. 3).

Closed reduction in patients from group 2 was conducted with the use of standard splints mounted to
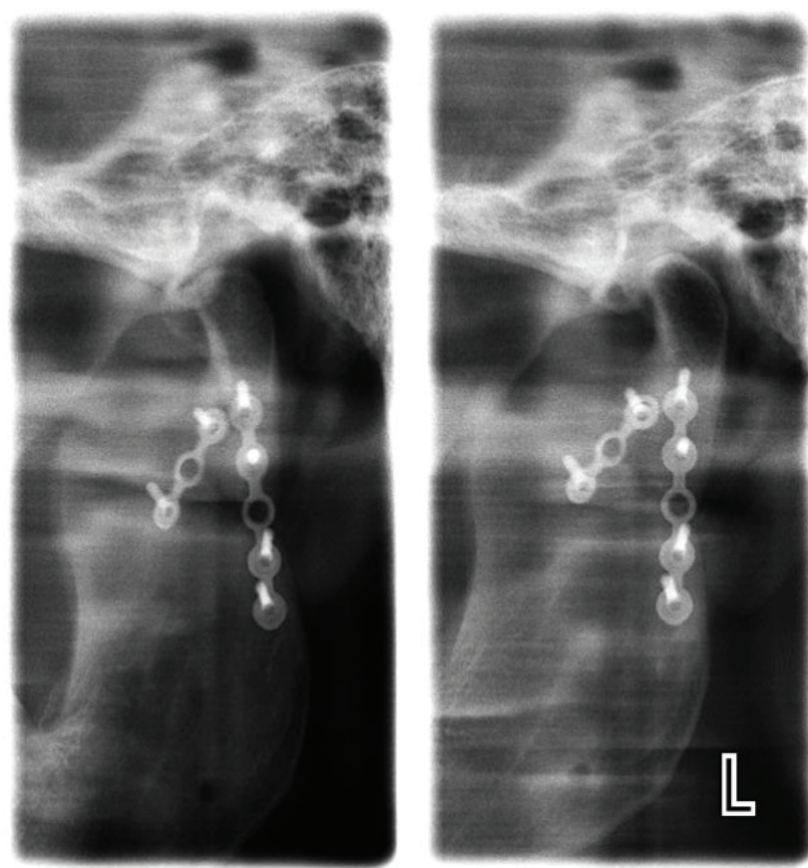

Fig. 3. X-ray image (projection of the temporomandibular joint) revealing a fixed subcondylar fracture on the left side

the upper and lower arch teeth with wire loops and by applying elastic maxillomandibular fixation. The patients were recommended a liquid diet and to report to weekly follow-up appointments in order to replace maxillomandibular fixation. Standard splints were removed after 4-5 weeks.

\section{Axiographic examination}

The key element of the examination was a follow-up appointment after 6 months from the surgery or from the conclusion of treatment by closed reduction. An axiographic examination was performed by means of the $\mathrm{Ca}-$ diax Compact II ${ }^{\circledR}$ (Gamma Medizinisch, Vienna, Austria) system to assess the mandibular dynamic pattern (the arbitrary hinge axis of TMJ) in 3 planes (Fig. 4).

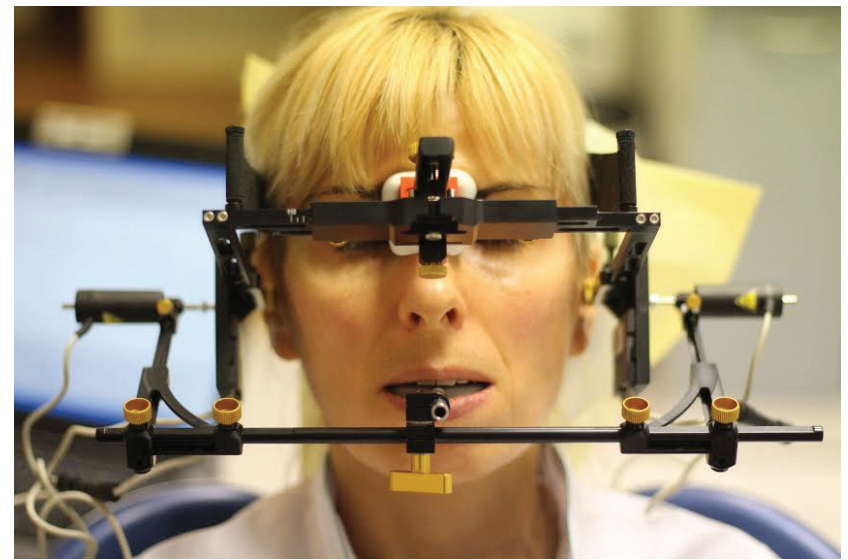

Fig. 4. Registration of mandibular movement (the condylar path) by means of Cadiax Compact $\|^{\circledR}$ 
This system is comprised of the upper and lower face bow, special electronic plates and telescopic markers. The lower face bow is mounted to the lower teeth with the use of a paraocclusal clutch, which does not disturb the natural occlusal support zones and enables the registration of the entire range of movement in protrusion, laterotrusion and opening from the so-called reference position to the maximum range. ${ }^{16}$

After the performance of the axiographic analysis, the data was collected and the analyses of the results were carried out using the PQStat v. 1.6 statistical package (PQStat Software, Poznań, Poland). The range of the condylar path in the sagittal plane (mandibular opening movement/closing movement) [in $\mathrm{mm}$ ], depending on the side, was analyzed using the Student's t-test for related variables. The range of the condylar path in the sagittal plane [in $\mathrm{mm}$ ], depending on the group of patients, was compared by means of the analyses of variances for repeated measurements with grouping factors, that is, a group with respect to the method of treatment, type of fracture, trauma-treatment initiation time and the employment of mandibular immobilization (before/after treatment). For significant results, the test probability was adopted at the level of $\mathrm{p}<0.05$, and for highly significant results, the test probability was adopted at the level of $\mathrm{p}<0.01$.

\section{Results}

On the basis of the inclusion and exclusion criteria, the study included 60 patients (Table 1).

There was a significant difference $(\mathrm{F}=5.36 ; \mathrm{p}=0.024)$ in the length of the condylar path in the sagittal plane $[\mathrm{mm}]$, depending on the method of condylar fracture treatment. The values were higher in the case of open reduction than in the case of closed reduction. The difference between the left and right side was not signifi-

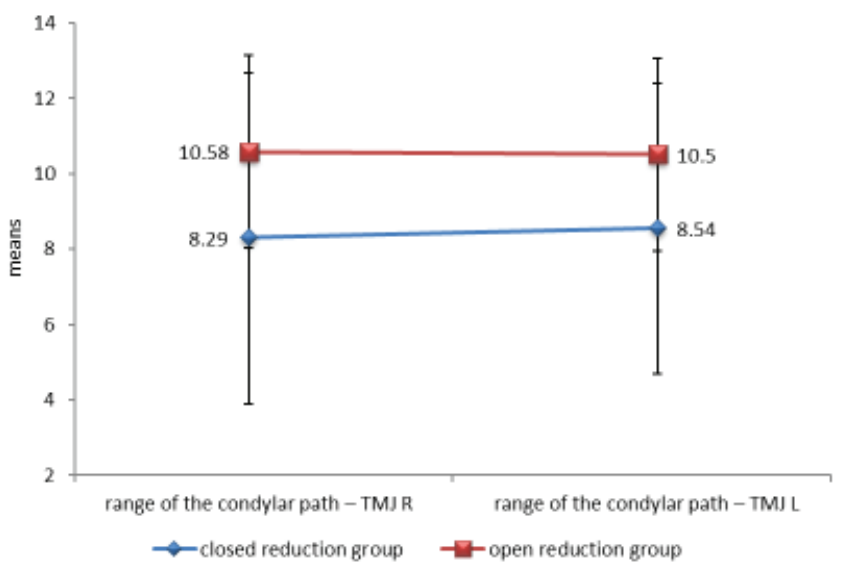

Fig. 5. Range of the condylar path in the sagittal plane [mm], depending on the group of patients with respect to applied treatment

cant $(\mathrm{F}=0.04 ; \mathrm{p}=0.844)$ and the interaction between the group and the side of measurement was not significant as well ( $\mathrm{F}=0.15 ; \mathrm{p}=0.698)$ (Fig. 5).

In the follow-up examination half a year after the conclusion of treatment, TMJ clicks were found in 35\% of the subjects, malocclusion was observed in $15 \%$ and the mandibular opening trajectory was described as asymmetric in the majority of the subjects (52\%).

There was a significant difference $(\mathrm{F}=2.71 ; \mathrm{p}=0.029)$ in the results of the condylar path in the sagittal plane [mm] depending on the type of fracture. In the case of unilateral fractures, the results were higher (significantly longer condylar path) than in the case of bilateral fractures. The difference between the left and right side was not significant $(\mathrm{F}=0.11 ; \mathrm{p}=0.740)$, and the interaction between the group and the side of measurement was not significant as well ( $\mathrm{F}=0.65 ; \mathrm{p}=0.661)$ (Fig. 6).

The majority of the subjects, i.e., $56.67 \%$, started treatment after more than 3 days from the trauma. In the statistical analysis, a significant difference

Table 1. Study group summary (group I - open reduction; group II - closed reduction)

\begin{tabular}{|c|c|c|c|c|c|c|c|c|c|}
\hline \multicolumn{10}{|c|}{ Study group summary I - open reduction, II - closed reduction } \\
\hline \multicolumn{2}{|r|}{ Examined parametr } & $n(\%)$ & I & II & \multicolumn{2}{|c|}{ Examined parametr } & $n(\%)$ & I & II \\
\hline \multicolumn{2}{|c|}{ age (arithmetic mean) } & 33.30 & 35 & 32 & \multirow{2}{*}{$\begin{array}{l}\text { preoperative immobilisation } \\
\text { (open reduction group) }\end{array}$} & no & $26(65 \%)$ & 26 & 0 \\
\hline \multirow{2}{*}{ gender } & women & $24(40 \%)$ & 12 & 12 & & yes & 14 (35\%) & 14 & 0 \\
\hline & men & $36(60 \%)$ & 28 & 8 & \multirow{2}{*}{$\begin{array}{l}\text { postoperative immobilisation } \\
\text { (open reduction group) }\end{array}$} & no & $7(17.5 \%)$ & 7 & 0 \\
\hline \multirow{6}{*}{$\begin{array}{l}\text { type of } \\
\text { fracture }\end{array}$} & unilateral condylar head fracture & $8(14 \%)$ & 2 & 6 & & yes & $33(82.5 \%)$ & 33 & 0 \\
\hline & bilateral condylar head fracture & $5(8 \%)$ & 2 & 3 & \multirow{2}{*}{$\begin{array}{l}\text { follow-up examination: } \\
\text { TMJ clicks }\end{array}$} & no & $39(65 \%)$ & 25 & 14 \\
\hline & unilateral condylar neck fracture & $18(30 \%)$ & 13 & 5 & & yes & $21(35 \%)$ & 15 & 6 \\
\hline & bilateral condylar neck fracture & $5(8 \%)$ & 4 & 1 & \multirow{2}{*}{$\begin{array}{l}\text { follow-up examination: } \\
\text { mandibular opening trajectory }\end{array}$} & symmetric & $29(48 \%)$ & 23 & 6 \\
\hline & unilateral subcondylar fracture & $17(28 \%)$ & 13 & 4 & & asymmetric & $31(52 \%)$ & 17 & 14 \\
\hline & bilateral subcondylar fracture & $7(12 \%)$ & 6 & 1 & \multirow{2}{*}{$\begin{array}{l}\text { follow-up examination: } \\
\text { malocclusion }\end{array}$} & no & $51(85 \%)$ & 33 & 18 \\
\hline \multirow{3}{*}{$\begin{array}{l}\text { trauma- } \\
\text { treatment } \\
\text { initiation } \\
\text { time }\end{array}$} & up to $24 \mathrm{~h}$ & $7(12 \%)$ & 5 & 2 & & yes & $9(15 \%)$ & 7 & 2 \\
\hline & up to 3 days & 19 (32\%) & 12 & 7 & \multirow{2}{*}{$\begin{array}{l}\text { range of condylar path } \\
\text { (arythmetic mean) }\end{array}$} & TMJ right & 9.06 & 10.6 & 8.29 \\
\hline & above 3 days & $34(56 \%)$ & 23 & 11 & & TMJ left & 9.20 & 10.5 & 8.54 \\
\hline
\end{tabular}




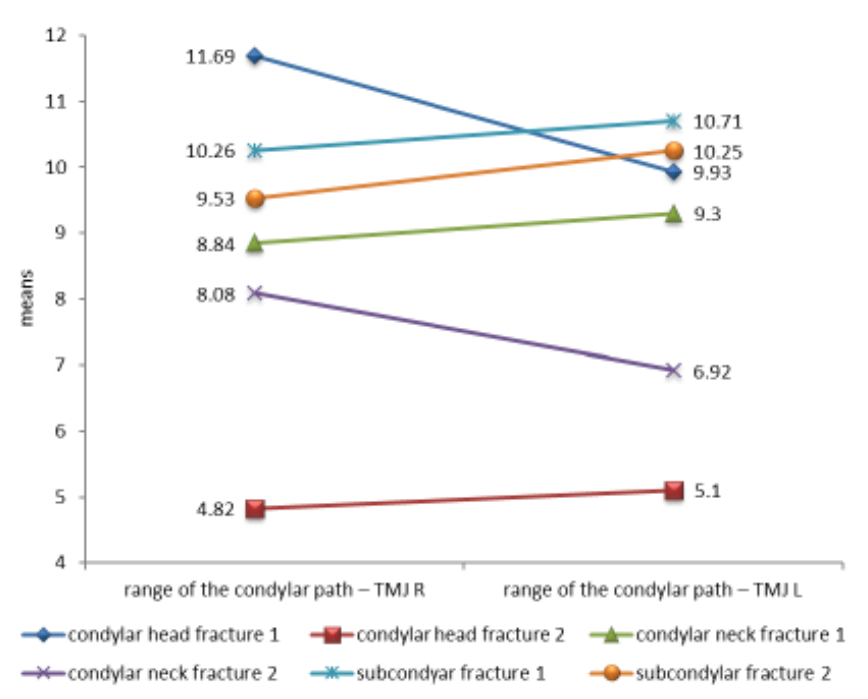

Fig. 6. Range of the condylar path in the sagittal plane $[\mathrm{mm}]$ depending on the group of patients with respect to type of fracture

$(\mathrm{F}=0.63 ; \mathrm{p}=0.534)$ of the ranges of the condylar path in the sagittal plane depending on the time which passed from the trauma to the treatment initiation, was not observed (Fig. 7).

The analysis of the correlation between the range of the condylar path and the employment of pre- and postoperative maxillomandibular immobilization in the open reduction group did not reveal any significant differences. There was a significant difference $(\mathrm{F}=1.20 ; \mathrm{p}=0.281)$ in the results of the condylar path in the sagittal plane [mm] depending on preoperative immobilization. A significant difference $(\mathrm{F}=0.72 ; \mathrm{p}=0.401)$ in the results of the condylar path in the sagittal plane [mm], depending on postoperative immobilization, was not found as well. The difference between the left and right side was not significant $(\mathrm{F}=0.25 ; \mathrm{p}=0.622)$ and the interactions between the groups and the side of measurement were not significant, either $(\mathrm{p}>0.005)$.

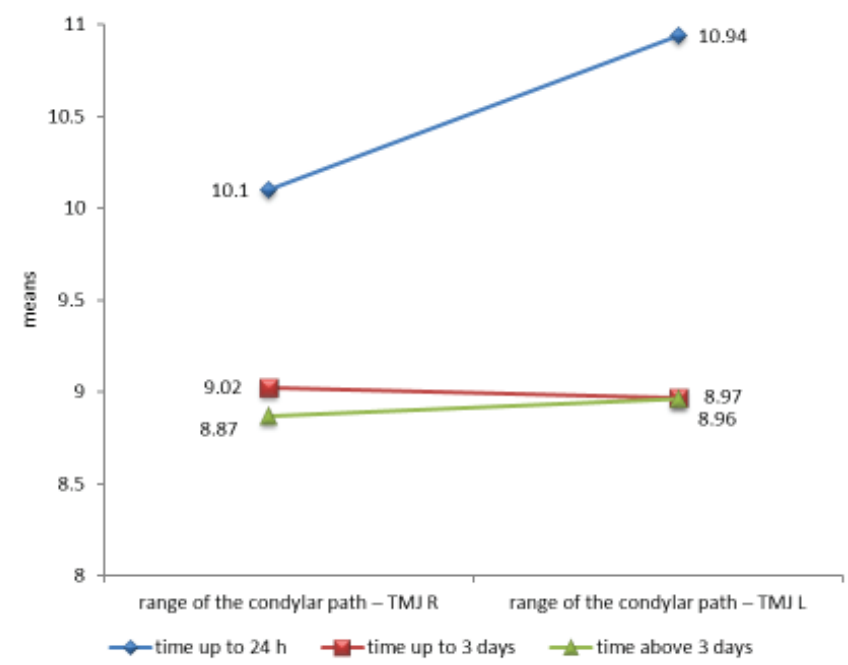

Fig. 7. Range of the condylar path in the sagittal plane [mm], depending on the group of patients with respect to time from fracture to the initiation of treatment

\section{Discussion}

The results of the above examination show the superiority of the open reduction method of condylar fracture treatment in the context of the later return of the stomatognathic system to full function. A statistically significant larger range of the condylar path was observed in patients after the open reduction of fractures compared to patients treated by closed reduction.

According to other authors, the closed reduction method of treatment is recommended in particular clinical situations such as: condylar process fractures, which do not cause the shortening of their length, fractures without dislocation, condylar head fractures (intra-articular) without the possibility of the osteosynthesis of tiny fragments and fractures in children and adolescents. ${ }^{17}$ What is more, some authors even prefer the conservative method of treating condylar fractures in children. There have been studies recently proving a well-tolerated removal splint therapy which enabled good occlusion in all the patients, along with unimpaired function and good development of the mandible in those patients. ${ }^{18}$

In spite of the many advantages, the open reduction method of condylar process osteosynthesis has its limitation because it involves the risk of damaging crucial periarticular structures. In the above studies, a retromandibular incision was used in patients treated by open reduction. The skin, the subcutaneous tissue and the fascia in the area behind the mandibular angle were incised, the masseter muscle was delaminated and access to the place of fracture was gained through the blunt dissection of tissues. Schneider et al. consider the lack of explicitly the best surgical approach (retromandibular, preauricular, intraoral) and difficulties in the repositioning of chipped fragments to be the main causes of the controversies over open reduction of fractures. ${ }^{15}$ Simultaneously, the authors draw attention to the fact that the more rarely used intraoral approach is justified only in situations of the lateral dislocation of a fractured process and the shortening of the mandibular ramus. Chrcanovic, on the other hand, states that each time the articular disc, which acts as a barrier preventing ankylosis of TMJ, should be repositioned intraoperatively. ${ }^{17}$ The lateral pterygoid muscle should not be delaminated from a chipped fragment because it impairs the vascularization of the bone and delays the regeneration of the masticatory muscles, which may have an impact on mandibular mobility. He et al., examining patients with condylar fractures (intra-articular), came to the conclusion that stable miniplate osteosynthesis is the best method of treating such fractures. ${ }^{19}$ It enables, i.a., the reconstruction of the proper height of the condylar process and restores the proper function of the temporomandibular joint. In order to achieve this, a few conditions must be met: good intraoperative visibility, stable repositioning 
without damaging the articular surface of he process and the lateral pterygoid muscle, and the repositioning of the articular disc.

In another study, Throckmorton and Ellis analyzed a group of 136 patients with a unilateral condylar fracture after open reduction and closed reduction. ${ }^{20}$ The main aim of their research was the qualitative and quantitative assessment of mandibular movements in a given group. They observed a gradual return to proper function during the subsequent follow-up appointments after 6 months and 1,2 , and 3 years. What is significant, the rehabilitation was faster in patients treated with open reduction than in patients treated by means of the closed reduction method but the full rehabilitation of the range of mandibular movements was achieved only after 3 years from the conclusion of treatment. Sforza et al. also raised the subject of the qualitative assessment of mandibular dynamics in a group of patients after open reduction and the rehabilitation of condylar fractures. ${ }^{21}$ The researchers analyzed the ranges of maximum mandibular opening, distinguishing the rotational and translational components of this movement. They also examined, using electromyography (EMG), the tone of the masticatory muscles and neck while clenching the teeth (MVC - maximum voluntary clenching). In comparison to the control group (healthy subjects), the work of the masticatory muscles in the EMG examination in subjects from the study group was characterized by larger asymmetry, which translated into bigger mandibular deviations from the symmetry line in the position of maximum mandibular opening. In our research, we observed a high percentage of subjects with an asymmetric trajectory of mandibular opening (52\%) and clicks in the temporomandibular joint, which may prove the rehabilitation of the stomatognathic system to be incomplete or improper. Particularly persistent clicks in the temporomandibular joint in patients treated by closed reduction may prove the articular disc and articular disc ligaments, together with the chipped fragment of the condylar process, to be irreversibly dislocated.

What draws attention is the mean range of the condylar path in the sagittal plane observed in our study, which amounted to $9.06 \mathrm{~mm}$ for the right TMJ and $9.20 \mathrm{~mm}$ for the left TMJ, respectively, and was below the adopted norm for the range of this movement, which amounts to $10-16 \mathrm{~mm} .{ }^{10,11}$ That means that after half a year from the conclusion of the fundamental treatment, the majority of patients still demonstrated considerably restricted mandibular mobility.

What matters greatly in the regeneration of the temporomandibular joints after condylar fractures is the widely understood physical therapy implemented from the early postoperative days, which is also emphasized by other authors. ${ }^{15,22-24}$ In our study group, each patient was subject, in the period of hospitalization, to physical therapy treatments: biostimulation laser therapy and light therapy (the Bioptron ${ }^{\circledR}$ lamp, Bioptron ${ }^{\circledR}$ AG, Switzerland) adjusted to the early complications observed after the surgery (pain, hematoma, edema, wound dehiscence). Each time, the patient was recommended the rehabilitation of the masticatory muscles through active and passive muscular exercises (mechanotherapy) and muscle selfmassages. It was also recommended to start the following exercises even 2-3 days after the surgery:

- active opening, protrusion and mediotrusion performed by the patient in front of a mirror in order to control the range and straight trajectory of the movements;

- in the case of a lack of functional progress on the $7^{\text {th }}$ day after the surgery, the implementation of passive, mild therapy involving stretching with fingers, spatulas or wooden wedges.

The effectiveness of these treatments depends largely on patients' self-discipline. Unfortunately, we often observed failure to comply with the recommendations to do muscular exercises in our study group, which also explains the restricted mobility of TMJ in these patients 6 months after the conclusion of treatment.

The axiographic examination performed revealed a shortening of the translational component of the condylar path in subjects from the study group. It should be stressed that proper masticatory function is conditioned by the 3-dimensional interaction of translational movements of both joints. If the translation in the joint is disturbed, masticatory function will be impaired. ${ }^{10}$ Moreover, combining the work of both joints means that the impairment of the function of one of them leads to the impairment of the work of the entire musculo-articular system.

Similar observations were made by Hochban et al. during the examination of patients with condylar fractures treated by open reduction from the intraoral approach and by closed reduction. ${ }^{25}$ In the group treated by closed reduction, he found that in $20 \%$ of the subjects, the length of the condylar path had a value of only $1 / 3$ of the proper range, while in $8 \%$ of the subjects the only possible movement of TMJ was the rotation of the mandibular head. It had an influence on the considerable impairment of mandibular dynamics in these patients, including masticatory function. In our research, in the group treated by open reduction, a limitation of the translation movement in the joint was also observed but general clinical assessment revealed that these patients recovered better.

Conclusions from this research confirm the superiority of the open reduction method of treating condylar fractures over closed reduction in the context of the rehabilitation of TMJ function, which corresponds with the reports of other authors. ${ }^{15,20,21,23}$ Open reduction compared to closed reduction disturbed the function of the stomatognathic system and mandibular dynamics to a lesser degree. However, there is still a need to improve the surgical technique in order to limit the traumatization of sensitive periarticular structures. 


\section{References}

1. Lindahl L. Condylar fractures of the mandible. Int J Oral Surg. 1977;6:12-21.

2. Andersson L, Kahnberg KE, Pogrel MA, eds. Oral and Maxillofacial Surgery. Wiley-Blackwell; 2010.

3. Sharif MO. Interventions for the treatment of fractures of the mandibular condyle. Cochrane Database Syst Rev. 2010;14:4.

4. Silvennoinen $U$, lizuka $T$, Lindqvist $C$, Oikarinen K. Different patterns of condylar fractures: An analysis of 382 patients in a 3-year period. J Oral Maxillofac Surg. 1992;50:1032-1037.

5. Abdel-Galil K, Loukota R. Fractures of the mandibular condyle: Evidence base and current concepts of management. Br J Oral Maxillofac Surg. 2010;48:520-526.

6. Zachariades N. Fractures of the mandibular condyle: A review of 466 cases. Literature review, reflections on treatment and proposals. J Craniomaxillofac Surg. 2006;34:421-432.

7. Vesnaver A, Ahčan U, Rozman J. Evaluation of surgical treatment in mandibular condyle fractures. J Craniomaxillofac Surg. 2012;40;522-529.

8. Chen CT, Feng CH, Tsay PK, Lai JP, Chen YR. Functional outcomes following surgical treatment of bilateral mandibular condylar fractures. Int J Oral Maxillofac Surg. 2011;40:38-44.

9. Belli E, Matteini C, Incisivo V. Orthodontic-surgical treatment after posttraumatic bilateral condylectomy of the mandible in an adult patient. J Craniofac Surg. 2003;14:55-62.

10. Slavicek R. The Masticatory Organ. Klosterneuburg: Gamma Medizinisch-wissenschaftliche Fortbildungs AG; 2002.

11. Gsellmann B, Schmid-Schwap M, Piehslinger E, Slavicek R. Lengths of condylar pathways measured with computerized axiography $\left(\mathrm{CADIAX}^{\circledR}\right)$ and occlusal index in patients and volunteers. J Oral Rehabil. 1998;25:146-152.

12. Bernhardt O, Küppers N, Rosin M, Meyer G. Comparative tests of arbitrary and kinematic transverse horizontal axis recordings of mandibular movements. J Prosthet Dent. 2003:89:175-179.

13. Krzemień J, Baron S. Axiographic and clinical assessment of temporomandibular joint function in patients with partial edentulism. Acta Bioeng Biomech. 2013;15:19-26.

14. Thieme KM, Kubein-Meesenburg D, Ihlow D, Nagerl H. Is a "movable hinge axis" used by the human stomatognathic system? Acta Bioeng Biomech. 2006;8:13-25.

15. Schneider M, Lauer G, Eckelt U. Surgical treatment of fractures of the mandibular condyle: A comparison of long-term results following different approaches - functional, axiographical, and radiological findings. J Craniomaxillofac Surg. 2007;35:151-160.

16. Han BJ, Kang H, Liu LK, Yi XZ, Li XQ. Comparisons of condylar movements with the functional occlusal clutch and tray clutch recording methods in CADIAX system. Int J Oral Sci. 2010;2:208-214.

17. Chrcanovic BR. Open versus closed reduction: Diacapitular fractures of the mandibular condyle. Oral Maxillofac Surg. 2012;16:257-265.

18. Zhao YM, Yang J, Bai RC, Ge LH, Zhang Y. A retrospective study of using removable occlusal splint in the treatment of condylar fracture in children. J Craniomaxillofac Surg. 2014;42:1078-1082.

19. He D, Yang C, Chen M, Bin J, Zhang X, Qiu Y. Modified preauricular approach and rigid internal fixation for intracapsular condyle fracture of the mandible. J Oral Maxillofac Surg. 2010;68:1578-1584.

20. Throckmorton GS, Ellis E. Recovery of mandibular motion after closed and open treatment of unilateral mandibular condylar process fractures. Int J Oral Maxillofac Surg. 2000;29:421-427.

21. Sforza C, Tartaglia GM, Lovecchio N, et al. Mandibular movements at maximum mouth opening and EMG activity of masticatory and neck muscles in patients rehabilitated after a mandibular condyle fracture. J Craniomaxillofac Surg. 2009;37:327-333.

22. Kyzas PA, Saeed A, Tabbenor O. The treatment of mandibular condyle fractures: A meta-analysis. J Craniomaxillofac Surg. 2012;40:438-452.

23. Handschel J, Rüggeberg T, Depprich R, et al. Comparison of various approaches for the treatment of fractures of the mandibular condylar process. J Craniomaxillofac Surg. 2012;40:397-401.

24. Shen L, Li P, Li J, Long J, Tian W, Tang W. Management of superolateral dislocation of the mandibular condyle: A retrospective study of 10 cases. J Craniomaxillofac Surg. 2014;42:53-58.

25. Hochban W, Ellers M, Umstadt HE, Juchems KI. Surgical reposition and fixation of mandibular condyle fractures via intraoral approach. Fortschr Kiefer Gesichtschir. 1996;41:80-85 [in German] 
